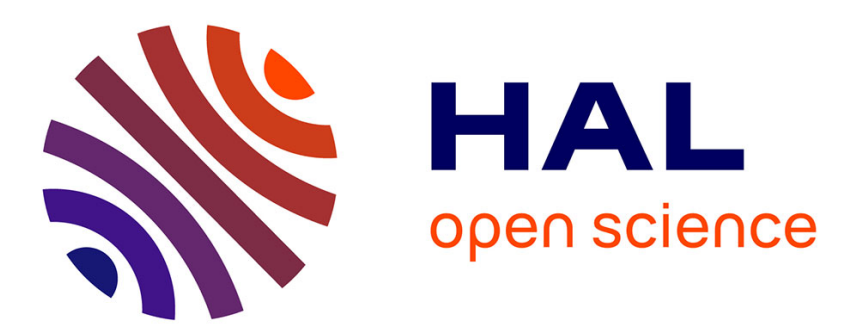

\title{
Contribution of goethite to laser-induced stone yellowing
}

Cécile de Oliveira, Véronique Vergès-Belmin, Jacques Lafait, Miko Swider, Christine Andraud, Aurélie Tournié, Laurence Galoisy

\section{To cite this version:}

Cécile de Oliveira, Véronique Vergès-Belmin, Jacques Lafait, Miko Swider, Christine Andraud, et al.. Contribution of goethite to laser-induced stone yellowing. Applied physics. A, Materials science \& processing, 2016, 122 (4), pp.467. 10.1007/s00339-016-9818-z . hal-01298670

\section{HAL Id: hal-01298670 https://hal.sorbonne-universite.fr/hal-01298670}

Submitted on 6 Apr 2016

HAL is a multi-disciplinary open access archive for the deposit and dissemination of scientific research documents, whether they are published or not. The documents may come from teaching and research institutions in France or abroad, or from public or private research centers.
L'archive ouverte pluridisciplinaire HAL, est destinée au dépôt et à la diffusion de documents scientifiques de niveau recherche, publiés ou non, émanant des établissements d'enseignement et de recherche français ou étrangers, des laboratoires publics ou privés. 


\title{
Contribution of goethite to laser-induced stone yellowing
}

\author{
C. de Oliveira · V. Vergès-Belmin · J. Lafait · M. Swider · C. Andraud \\ · A. Tournié · L. Galoisy
}

April 5, 2016

\begin{abstract}
The development of the laser technology for stone cleaning purposes has been undermined in the recent years because the technique occasionally conveys a yellow hue to the cleaned surfaces. Several components of black gypsum crusts have been suggested to be potentially responsible for the phenomenon, more specifically some granular fractions of their components. The contribution of these particles to laser yellowing is studied here on powdery deposits collected at Saint-Denis Basilica (France). The powder is characterized by optical and scanning electron microscopy, Xray diffraction and Raman spectroscopy before and after the laser irradiation. Irradiation of the samples results in a significant yellowing, along with particle fragmentation, while no mineralogical change is evidenced by powder diffractometry. Hematite and goethite micro-Raman signatures ob-
\end{abstract}

\section{Vergès-Belmin}

Centre de recherche en conservation : Laboratoire de recherche des monuments historiques, (CRC:LRMH), CNRS/USR 3224 - Sorbonne Universités - 29, rue de Paris - 77420 Champs sur Marne - FRANCE Tel.: +3316037 77 80/95

Fax: + 33160377799

E-mail: veronique.verges-belmin@culture.gouv.fr

C. de Oliveira

Centre de recherche en conservation : Laboratoire de recherche des monuments historiques, (CRC:LRMH), CNRS/USR 3224 - Sorbonne Universités - 29, rue de Paris - 77420 Champs sur Marne - FRANCE

\section{J. Lafait and M.Swider}

Sorbonne Universités, UPMC Univ Paris 06, CNRS, Institut des Nanosciences de Paris - 4, place Jussieu - 75252 Paris cedex 05 FRANCE

A. Tournié and C. Andraud

Centre de recherche en conservation: Centre de recherche sur la conservation des collections (CRC:CRCC), CNRS/USR 3224 - Sorbonne Universités - 36 rue Geoffroy-Saint-Hilaire - 75005 Paris - FRANCE

L.Galoisy

Sorbonne Universités, UPMC Univ Paris 06, CNRS, Institut de Minéralogie, de Physique des Matériaux et de Cosmochimie - 4, place Jussieu - 75252 Paris cedex 05 - FRANCE tained before laser irradiation are replaced after irradiation by a strong fluorescence in addition to weak goethite signatures in Raman spectra. The powdery deposit is further analyzed by diffuse reflectance spectrometry after a specific preparation which increases both its cohesion and its content in new phases potentially formed. The powdery material shows a phase with a spectral signature similar to goethite which subsides after laser irradiation. The yellow appearance caused by laser irradiation seems to be due, in part, to a selective elimination of the black components (soots) from the powdery deposit. This elimination reveals a colour which could be related to a pre-existing phase containing iron, possibly goethite or another phase containing iron and having the same spectral signature in the visible range.

Keywords laser cleaning $\cdot$ yellowing $\cdot$ goethite $\cdot$ hematite

\section{Introduction}

Laser cleaning devices made their entry in the field of stone conservation in the early seventies [1]. The technique allows removing soiling and black gypsum crusts in a very selective way, even though this advantage is not be immediately perceptible by naked eye, due to the minute scale of the preserved layers. Although very efficient and selective [2-8], the cleaning using Q-switched Nd:YAG laser devices operating at $1064 \mathrm{~nm}$ is sometimes criticized for the yellow hue it conveys to the stone, in contrast with other techniques such as micro-sandblasting or chemical pads $[2,5,6]$. This turned to become an issue in France, where restoration of the original color is of cultural concern [6,9-11]. Since the development of the laser tool in the early nineties, numerous investigations have been performed, and several propositions have been put forth on the yellowing phenomenon [12]. Nowadays, it is generally admitted that the effect is the result of 
an entire set of causes [13]. Among the latter, the laser transformation of the soiling materials themselves has been evidenced to be one of the mechanisms [14] but its exact contribution has not been thoroughly investigated so far, excepted by studies on laboratory model crusts [15] extremely simple in composition as compared to real black crusts.

According to the ICOMOS-ISCS glossary, black crusts are "Generally coherent accumulation of materials on the surface, which may include exogenic deposits in combination with materials derived from the stone $(. .$.$) . They are$ composed mainly of particles from the atmosphere, trapped into a gypsum $\left(\mathrm{CaSO}_{4} .2 \mathrm{H}_{2} \mathrm{O}\right)$ matrix" [16].These superficial layers have been extensively studied. For instance black crusts sampled from carbonate stone monuments subject to the Italian urban atmosphere contained on average $76 \%$ calcium sulphate dihydrate, $2 \%$ carbon from carbonates, $2,5 \%$ carbon besides carbonates (soots), and $19 \%$ other components. Among the latter, silica (quartz mainly) and aluminosilicates were found to be very abundant [17].

Gypsum, quartz, and calcite are components not reactive to the laser beam in the range of fluences consistent with the selective elimination of the black crusts from the substrate (ca. 0.5-1 J/cm2 for Q-switched Nd:YAG lasers at $1064 \mathrm{~nm}$ ). On the contrary, soots (impure carbon particles resulting from the incomplete combustion of hydrocarbons) strongly absorb the radiation at $1064 \mathrm{~nm}$ [18]. Similarly, metallic oxides are strongly reactive to this very same radiation [19], especially the iron oxides [14]. When hematite is applied as pure powder on laboratory gypsum samples, their surface turns yellow to black after laser irradiation [20]. It is thus likely that in the natural black crust presence of these species could be responsible for the laser yellowing of the sample.

From previous studies on laboratory model crusts and observation of laser cleaned stone surfaces, it has been shown that laser cleaning residues, if present, are mostly undetectable by commonly used analytical tools. In most publications on laser cleaning, the studies were based on observations of natural samples by optical microscopy, XRD or SEM (see the review by Siano et al. [21]), but the authors could not detect any neo-formed phase. It is only on artificial crust models composed of gypsum, hematite and graphite that an iron-rich neo-formed phase, magnetite $\left(\mathrm{FeO} . \mathrm{Fe}_{2} \mathrm{O}_{3}\right)$ was evidenced $[14,15]$. The explanation of the yellow color was not clear though, since the only phase detected in [15], magnetite, is black, not yellow. A contribution of the iron compounds remains probable but so far no yellow species has been identified.

Iron-rich reactive phases present in the particulate fraction of natural black crusts are in fact of particular interest and their role should be further studied, but their low concentration makes this study quite difficult. In that context, dust deposits, which are fairly easy to collect (Fig.1), show-

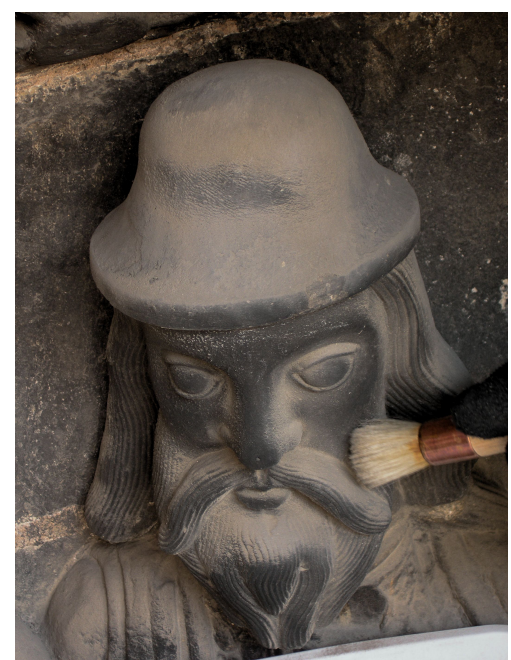

Fig. 1 Collecting powdery deposit sitting on the top of black crusts at Saint Denis Basilica.

ing a composition extremely close to black crusts but richer in particulate fraction, provide a convenient material for further studying laser yellowing. Our present research has been oriented towards the study of such powdery deposits collected on the sculptures of Saint-Denis basilica, the black crust of which had already been the subject of several studies [22].

The chemical composition of Saint-Denis powdery deposits is close to the one found in their indurated counterpart, although the former are richer in iron and carbon (Table 1). Presence of sulphur corresponds to gypsum, $\mathrm{CaSO}_{4} \cdot 2 \mathrm{H}_{2} \mathrm{O}$ (that would amount to $43 \%$ in the dust, $58 \%$ in the black crust). Iron content in the black crust $(0.74 \%)$ is of the same order of magnitude as in Venetian black crust studied by Fassina et al. [25]: 0.06-1.45\% quantified by atomic absorption. We note that he powdery deposit contains 3 times more iron than the corresponding black crust.

In the present study, we apply an original methodology to studying laser induced yellowing of Saint-Denis powdery deposits. SEM/XRD/Raman analyses are performed on the powdery samples before/after irradiation after removal of their gypsum fraction. In a second step, we synthesized gypsum crusts from the natural dust and studied its spectral characteristics using diffuse reflectance spectrometry.

\section{Materials and methods}

The powdery deposit comes from the western portal of SaintDenis Basilica (France). It formed between ca. 1955 (date of the last restoration of the portal) and 2007 (date of sampling) on sub-horizontal parts of the outdoors sculptures protected from rainfall surfaces, in a strongly polluted urban environment. 


\begin{tabular}{cccccccc}
\hline & $\begin{array}{c}\mathrm{C}^{*} \\
(\mathrm{wt} \%)\end{array}$ & $\begin{array}{c}\mathrm{N}^{*} \\
(\mathrm{wt} \%)\end{array}$ & $\begin{array}{c}\mathrm{S}^{*} \\
(\mathrm{wt} \%)\end{array}$ & $\begin{array}{c}\mathrm{Fe}^{* *} \\
(\mathrm{wt} \%)\end{array}$ & $\begin{array}{c}\mathrm{CO} 3^{* * *} \\
(\mathrm{wt} \%)\end{array}$ & $\begin{array}{c}\text { Mass loss } \\
200^{\circ} \mathrm{C}(\mathrm{wt} \%)\end{array}$ & $\begin{array}{c}\text { Mass loss } \\
1150^{\circ} \mathrm{C}(\mathrm{wt} \%)\end{array}$ \\
\hline Black crust & 2.96 & $<0.01$ & 10.83 & 0.74 & $<1$ & 17.9 & 27.3 \\
Powdery dep. & 4.23 & 0.19 & 8.03 & 2.56 & 1 & 12.8 & 35.1 \\
\hline
\end{tabular}

Table 1 Composition of black crusts and powdery deposits from Saint-Denis Basilica. After [23] and [24].

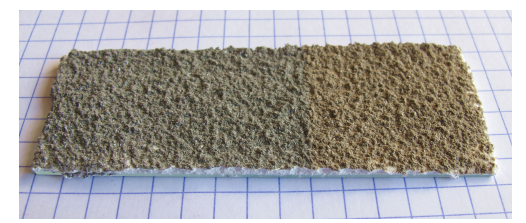

Fig. 2 A partially laser irradiated artificial crust sample. Grid size: 5x5 $\mathrm{mm}$

\subsection{Samples preparation}

Diffuse reflectance spectroscopy more reliable and easier to perform on flat, relatively large and cohesive samples. To bring such conditions, the powdery sample was dry mixed at a ratio 50/50 wt \% with calcium sulfate hemihydrate $\left(\mathrm{CaSO}_{4}\right.$ $1 / 2 \mathrm{H}_{2} \mathrm{O}, 97+\%$ purity, Acros organics) and sprinkled upon a freshly prepared mixture of calcium sulfate hemihydrate with water, just before its setting into gypsum. This procedure allowed obtaining a flat indurated artificial gypsum crust, the microstructure and laser behavior of which is very close to the one of a real black crust (Fig.2).

In order to increase in the powdery samples the content of phases susceptible to be reactive to laser according to literature, it was necessary to remove their gypsum component. To that end, one gram of the sample was put in $100 \mathrm{ml}$ distilled water and kept at room temperature and under constant stirring for 72 hours, a time sufficient for gypsum to be completely dissolved. The suspension was then centrifuged. The supernatant was removed and replaced with an equivalent volume of distilled water, stirred, and then centrifuged again. This procedure was repeated at least four times, until no trace of gypsum could be found within the suspension by XRD diffractograms and SEM-EDS X-ray microfluorescence. The deposit sitting at the bottom of the centrifugation vessel i.e. the lixiviation residue - once dried in a ventilated oven at $60^{\circ} \mathrm{C}$, was ready for analysis. This procedure was followed both on bulk samples and on samples after laser irradiation.

The above procedure resulted in two types of samples: a flat artificial crust (AC) for diffuse reflectance spectroscopy, and lixiviation residues (LR) for XRD, Raman and SEMEDS analyses.

\subsection{Laser irradiation}

The AC samples are irradiated using a Q-switched Nd:YAG NL00 (1064 nm) laser, fitted with an articulated arm, from the French laser company Thomson CSF-BMI. This device produces pulses having duration from 6 to 15 nanoseconds and a maximum energy of 500 millijoules. The irradiation was performed on moistened samples at a pulse frequency of $10 \mathrm{~Hz}$, and fluences between 0,1 and $0,6 \mathrm{~J} / \mathrm{cm} 2$ as described in [20]; 150 pulses were applied per square centimeter. The Figure 2 shows an AC sample partly irradiated in those conditions.

The slightly moistened LR residue is placed in a closed glass petri box, and irradiated through the lid with the same fluencies as AC samples. This procedure, already used in

\subsection{Microstructural analyses and Raman spectrometry}

Optical microscope observations are performed on the LR samples with the microscope of the Raman spectrometer. The images are obtained under dark field/reflection conditions, which allow to visualize the colour of the analysed object without modification compared to naked eye observation. Scanning electron microscopy is performed on the LR samples using a JEOL JSM-5600 microscope fitted with a TRACOR energy dispersive spectrometer. Images are obtained in a backscattering configuration using a secondary electron (BSE) detector. X-ray diffraction is performed on the powdery deposit and on LR samples before and after irradiation with a Panalytical X'Pert MPD - Bruker D8 diffractometer fitted with a copper anode. Experimental conditions: 2Th/Th locked, step size $0.0062 \mathrm{Th}$, step nr: 6920, time/step: 3s, total scan: 6 h15.

Raman spectra are obtained with a Renishaw Raman micro-spectrometer fitted with two lasers (785nm and $532 \mathrm{~nm}$ ), using the extended mode, and exploring the part of the light spectrum between 200 and $1000 \mathrm{~cm}^{-1}$. The intensity of the beam is equal to or less than $1 \%$ of its full capacity with the x50 objective (power: 30 Watts). The exposure time is increased step by step, taking care not to cause any conversion of oxide grains, which would be clearly evidenced through color changes in the microscope observation. The resulting spectra are compared those given in the online database RRUFF1 and with the tables of peaks coordinates and spectra given in [26]. 


\subsection{Diffuse reflectance spectrometry}

The diffuse reflectance spectra are recorded in the range 180-3000 nm with a reflectance spectrometer Agilent Carry 5000 fitted with an integrating sphere. Color coordinates expressed in the $\mathrm{L}^{*} \mathrm{a} * \mathrm{~b}^{*}$ color system are calculated from the recorded data. In this color system, $L^{*}$ represents the brightness on a 0-100 scale, $\mathrm{a}^{*}$ represents the green-red scale with negative-positive values corresponding respectively to green and red intensities, and similarly $b^{*}$ stands for the blueyellow scale. The second derivative of the diffuse reflectance spectra was calculated in order to highlight weak absorption peaks and to eliminate the contribution of a wide continuum. This method has been successfully applied in [27] to the identification of the absorption peaks of the iron oxides and oxy-hydroxides. Here we have adapted this method as follows: the measured reflectance spectrum is first smoothed, then the second derivative is applied to $1 /$ total reflectance versus the wavelength. This method is expected to be capable of identifying compounds with iron oxides concentrations of $1 \%$ or less. The second derivative curve of hematite shows one typical minimum at $542 \mathrm{~nm}\left(18450 \mathrm{~cm}^{-1}\right)$, and goethite shows two minima at $495 \mathrm{~nm}\left(20200 \mathrm{~cm}^{-1}\right)$ and 423 $\mathrm{nm}\left(23640 \mathrm{~cm}^{-1}\right)$, see Figure 8 . Before any application and further study, the second derivative method is applied to an AC sample made out of pure hemihydrate. We have verified that the calcium sulfate hemihydrate spectrum contains no minimum susceptible to be attributed to any of the iron oxide phases which might be present in the natural powdery deposit or result from laser irradiation of the deposit.

\section{Results}

SEM / XRD / Raman analytical results on lixiviated residues are discussed first. Diffuse reflectance spectrometry results obtained from artificial crusts are discussed thereafter.

\subsection{Microstructure and mineralogy}

Before laser irradiation. After lixiviation, and before irradiation, the sample gets completely rid of its water soluble fraction, which, according to our estimation through weight measurements, initially represents $40 \%$ of its weight. The quartz $\left(\mathrm{SiO}_{2}\right)$ peaks largely dominate the XRD diffractograms. The minor phases are identified as orthoclase $\left(\mathrm{KAlSi}_{3} \mathrm{O}_{8}\right)$, albite $\left[\mathrm{Na}\left(\mathrm{AlSi}_{3} \mathrm{O}_{8}\right)\right]$, illite $\left[\mathrm{KAl}_{2} \mathrm{Si}_{3} \mathrm{AlO}_{10}(\mathrm{OH})_{2}\right]$, chlorite $\left[(\mathrm{Fe}, \mathrm{Mg}, \mathrm{Al})_{6}(\mathrm{Si}, \mathrm{Al})_{4} \mathrm{O}_{10}(\mathrm{OH})_{8}\right]$, and weddelite $\left(\mathrm{C}_{2} \mathrm{CaO}_{4}\right.$ $2 \mathrm{H}_{2} \mathrm{O}$ ). No crystallized iron containing phase was evidenced.

Under the optical microscope, the sample looks quite heterogeneous: it consists of a mixture of black and transparent grains (Fig.3). Red particles are quite numerous. Some

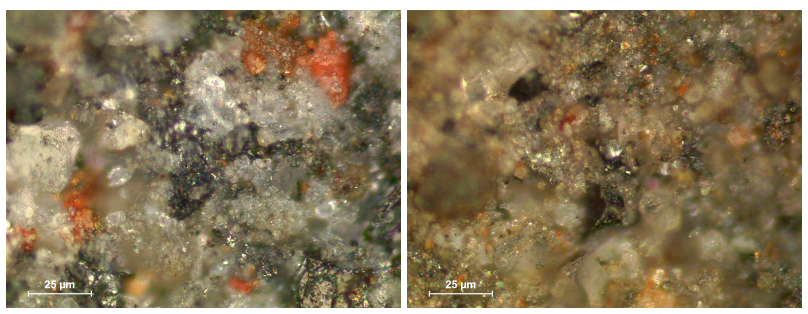

Fig. 3 Lixiviation residue of the powdery deposit, as seen under optical microscope, showing the size reduction and significant yellowing on the right image (laser-irradiated) with respect to the left image (nonirradiated).

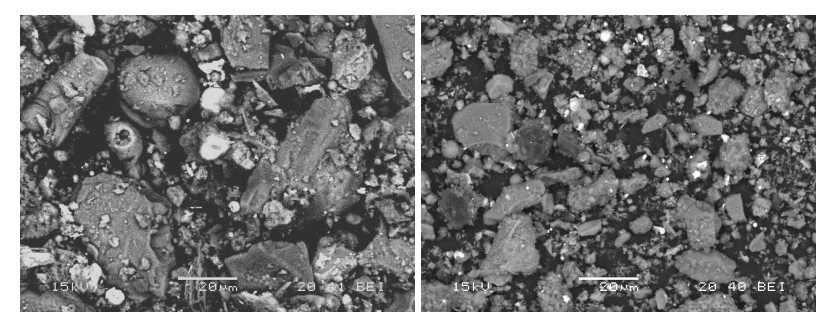

Fig. 4 SEM-BSE images of the lixiviation residue of the powdery deposit : non-irradiated (left), laser irradiated (right).

yellow-orange grains also appear more rarely. The size of all the coloured grains is in the range 5-25 micrometers.

SEM coupled with the X-ray micro-fluorescence observations and analyses confirm the efficiency of lixiviation, as sulfur is not anymore detected on fluorescence spectra. Particles of more or less angular shape (size range: one to several tens of micrometers) are dominant. The 5 to $20 \mu \mathrm{m}$ microspheres (fly ashes) are scarce. The major elements detected are silicon and aluminum. The iron peak is clearly visible in the fluorescence spectrum of particles which appear whiter in the BSE imaging mode. Otherwise iron is systematically detected as trace element in the whole sample. Calcium, magnesium, potassium and sodium are also encountered as frequent trace elements.

After laser irradiation. The X-ray diffractograms before and after irradiation look very much alike. This technique cannot detect any significant difference in the samples before and after irradiation. Under the optical microscope, an overall slight yellow hue can be observed (Fig.3). Red or orange particles of several tens of micrometers in size are less numerous, just as if most of them have been fractioned. Areas with a high concentration of yellow grains from one to ten micrometers in size can be observed occasionally. In the SEM observations, particles are smaller than before irradiation (Fig.4) and in the BSE mode, much smaller bright particles can be observed. They have no well defined shape and their diameter is about $1 \mathrm{~m}$. Once again, iron is systematically encountered as a trace element in the powder. 


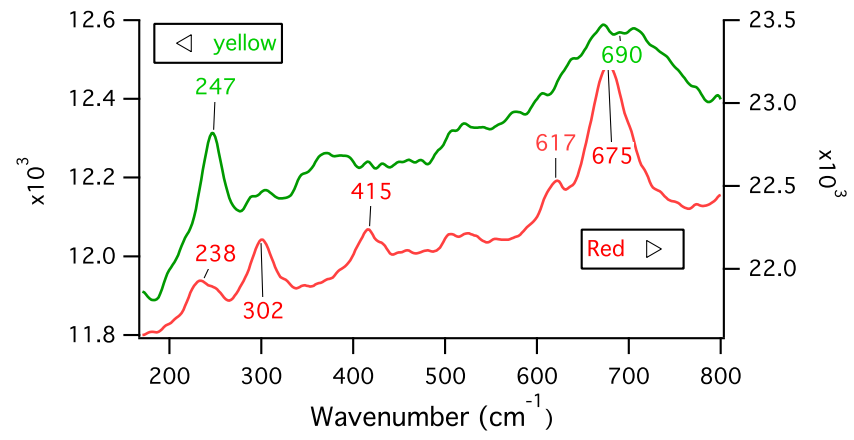

Fig. 5 Raman spectra of a red and a yellow particle from the lixiviation residue before laser irradiation.

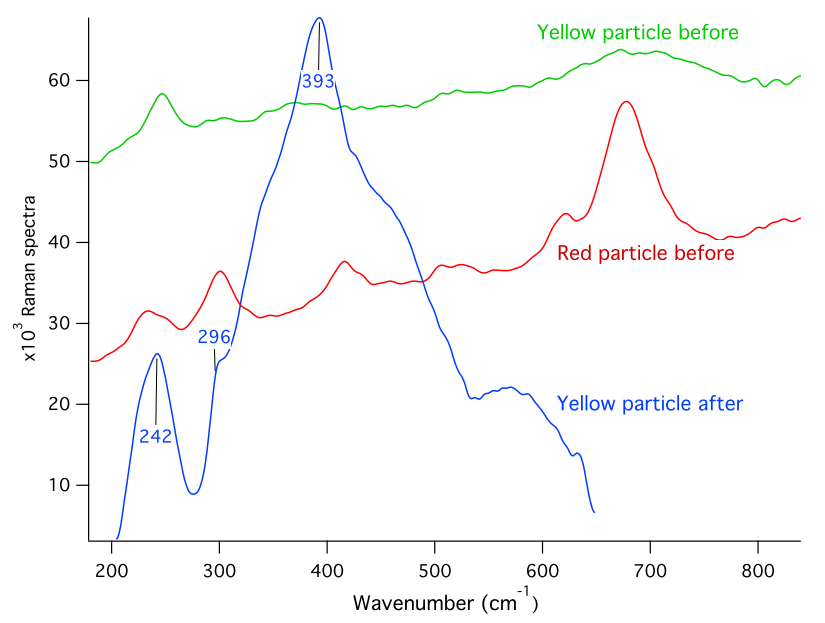

Fig. 6 Raman spectra of particles from lixiviation residues. Compared to spectra of the red and yellow particle (a.u.) obtained before irradiation (Fig.5), the spectrum of a yellow particle after irradiation shows a strong fluorescence.

\subsection{Micro-Raman spectroscopy}

Before irradiation, the main peaks in Raman spectra of hematite $\left(238,302,415\right.$ and $\left.617 \mathrm{~cm}^{-} 1\right)$ can be detected on red particles (Fig.5). On yellow grains, generally no Raman response is obtained, but presence of goethite $\left(247\right.$ and $\left.690 \mathrm{~cm}^{-1}\right)$ is evidenced in some scarce particles. After laser irradiation, the lixiviated powder does not show the presence of hematite grains anymore, although the yellow grains are still visible. By irradiation, the Raman shifts become dominated by a strong fluorescence, and goethite (242, 296 and $393 \mathrm{~cm}^{-1}$ ) can be detected in some grains (Fig.??). Since fluorescence has a broad emission and is much more intense than the Raman signal, already very low amounts of fluorescent species can impair the Raman scatter of a material.The strong fluorescence we observe after laser irradiation could thus be due to a very thin layer of an undetermined fluorescent material which covers the sample surface.



Fig. 7 Diffuse reflectance spectra of the artificial crust made from $50 \%$ calcium sulfate hemihydrate and 50\% powdery deposit, before and after irradiation. The Pure gypsum curve corresponds to an artificial crust made out $100 \%$ calcium sulfate hemihydrate.

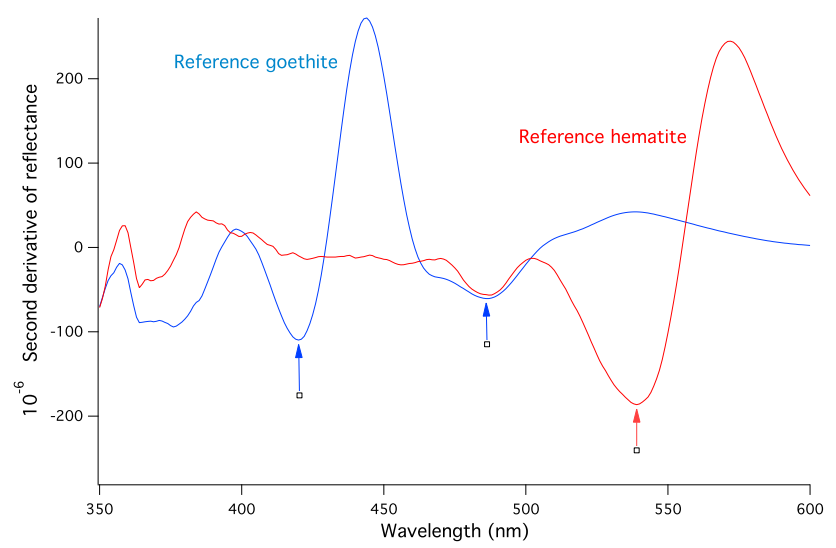

Fig. 8 Second derivative of the diffuse reflectance spectra of pure goethite and pure hematite pigments

\subsection{Diffuse Reflectance spectrometry}

The diffuse reflectance spectra obtained from the artificial crust before and after irradiation are shown on Fig.7.

Before irradiation, the sample has a reflectance ratio always less than $30 \%$, of the incident light whatever the wavelength. A slight upward slope of this curve is observed in the visible range. After irradiation, the reflectance of the sample greatly increases on the longer visible wavelengths. It takes then a steep slope in the visible range which is consistent with the observed yellow colour since the short wavelengths are absorbed. The reflectance spectrum of pure gypsum is quasi-uniform at $85 \%$ over the entire visible range.

L*a*b* values calculated from the diffuse reflectance spectra are reported in Table 2 . Consequent to the irradiation, all parameters increase significantly. The $a^{*}$ value being very low (0.5) its huge increase upon irradiation still leads to a very low value (1.5). So that this change is not perceptible to the human eye. $\mathrm{L}^{*}$ and $\mathrm{b}^{*}$ values are larger and 


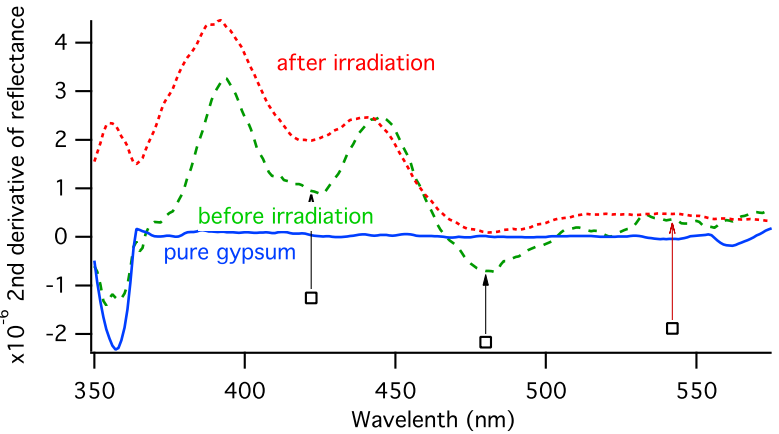

Fig. 9 Second derivative of the diffuse reflectance spectra from the artificial crust.

\begin{tabular}{lccc}
\hline & $\mathrm{L}^{*}$ & $\mathrm{a}^{*}$ & $\mathrm{~b}^{*}$ \\
\hline before irradiation & 57.6 & 0.5 & 4.5 \\
after irradiation & 84.6 & 1.9 & 17.2
\end{tabular}

Table 2 Color parameters L*a*b* of the artificial crust before and after laser irradiation.

their evolution is clearly perceptible: the surface changes on laser irradiation from dark gray to a dull yellow ochre hue.

The second derivative of the diffuse reflectance spectra obtained for pure goethite and pure hematite, shown on Fig.??, are taken as a reference. On the artificial crust made from the mixture calcium hemihydrate/St Denis powdery deposit, the inflections at 423 and $490 \mathrm{~nm}$ are observed both before and after laser irradiation (Fig.9). These inflections occur at the same wavelengths as the ones observed on second derivatives reflectance spectra of pure goethite (Fig.??). No inflection around $542 \mathrm{~nm}$, characteristic of the presence of hematite, appear before and after irradiation in the second derivative spectrum of the reflectance of this artificial crust (Fig.9).

\section{Discussion}

The composition of the powdery deposit of Saint-Denis is close to its black crust counterpart, although its gypsum content is smaller. The XRD spectrum is largely dominated by quartz, and crystallized iron compounds are not detected. As iron has been detected in Raman spectra under the form of hematite and goethite, this means that crystallized iron phases are not abundant enough to be identified by powder X-ray diffractometry (less than 5\%). Raman spectroscopy also allows associating - to a certain extent - the grains colour with their composition: goethite is detected in some yellow grains, although the majority of the latter do not show any specific Raman shift. Hematite is detected in most red grains, although its presence is scarce in the deposit. The analysis of diffuse reflectance spectra also tends to prove that it is goethite or a phase having the same spectral signa- ture that is the most abundant iron-containing phase in the powdery deposit.

These results are slightly but significantly different from what the literature tells us about iron compounds in pollution related deposits on monuments. Up to now, Iron has been commonly believed to occur in black crusts under the form of hematite. This was probably due to a mis-interpretation of the results of X-ray fluorescence analyses: 0.2 to $0.6 \%$ $\mathrm{Fe}_{2} \mathrm{O}_{3}$ were found in the black crusts from the Parthenon [28], while more recently $0.2-5 \% \mathrm{Fe}_{2} \mathrm{O}_{3}$ were found in black crusts from Germany and Hungary [29]. Hematite was mentioned as one of the compounds frequently deposited on stone surface in the form of colloidal particles [30], and $\mathrm{Fe}_{2} \mathrm{O}_{3}$ (probably hematite) was detected by micro-Raman on a natural black crust [31]. Analyses by X-ray fluorescence, as the ones reported above, conventionally provide the iron quantities referring to trivalent iron oxide $\mathrm{Fe}_{2} \mathrm{O}_{3}$. Nevertheless, this does not mean that iron occurs as hematite, a crystalline phase of iron oxides having precisely $\mathrm{Fe}_{2} \mathrm{O}_{3}$ as chemical formula. This mis-understanding has led to considering hematite as the main crystalline form of iron in black crusts, and has mislead several studies on the behavior of this iron oxide upon laser irradiation $[14,15]$. As a consequence, hematite has been suspected of being responsible for the laser yellowing effect, because this red pigment transforms and gets yellow on laser irradiation.

On our powdery sample, laser irradiation results in a fragmentation of the particles, and in a significant yellowing. The study of the reflectance spectra obtained from artificial crusts made of 50/50\% gypsum/powdery deposit mixtures gives surprising results. Before irradiation hematite is not detected on the second derivative spectra, and inflections attributed to goethite are present both before and after irradiation. These results tend to show that the yellow hue obtained upon laser irradiation might be due to the preservation (or uncovering) of goethite or of a mineral having the same spectral response after irradiation. Nevertheless this result is probably only a part of the explanation, as microRaman spectroscopy could discriminate between the presence of hematite and goethite before irradiation and goethite alone after irradiation. Actually a transformation of hematite $\left(\mathrm{Fe}_{2} \mathrm{O}_{3}\right)$ into goethite $(\mathrm{FeO} . \mathrm{OH})$ might occur, as is suggested also by the appearance of the typical goethite inflections on the second derivative of diffuse reflectance spectra after irradiation. This hypothesis looks nevertheless somewhat peculiar, because this reaction is not thermodynamically possible.

A significant yellowing has been obtained upon irradiation at $1064 \mathrm{~nm}$ of gypsum:hematite:graphite (3:1:1 vol. parts) mixtures by Klein et al. [14]. The yellowing of this mixture, far richer in iron oxides than natural black crusts, was related to the presence of spherical beads, a few tens of nanometers in diameter, over the irradiated surface. Al- 
though characterized as being rich in iron, the residues were not clearly identified. Also the transformation paths leading from red hematite particles to those beads remain unclear. We can note that the shape of the beads suggested a quick cooling from a melt material. Further, it is not clear how these beads of undefined color observed under the SEM could induce yellow hues on visual examination. Working on the laser irradiation of different kinds of pigments made from metallic oxides, Pouli et al. [19] found the same amorphous residues as those observed by Klein et al. and hypothesised that the metallic oxides are reduced under the $1064 \mathrm{~nm}$ laser irradiation. They pointed out a pronounced difference between the reaction of pigments under laser irradiation and upon heating. Indeed, in their opinion the transformation occurring when laser is used is predominantly a reduction, which is permitted by the very hot and oxygen-free plasma generated around the laser impact. Applying this hypothesis to experiments performed on mixtures hematite/gypsum and hematite/graphite/gypsum, two other research teams [15,32] confirmed a reduction of hematite into metallic iron inside the plasma generated by the laser beam. The metallic iron would then oxidize on cooling in contact with oxygen. For Zhang et al. [32], the reduction is made possible by the oxidation of carbon during the reaction, and after cooling, hematite forms again from the metallic iron. For Gracia et al. [22] the presence of carbon is not necessary: they observe in their experiments the production of phases having the same analytical signature, with or without carbon. According to them the oxidation leads to the formation of magnetite, $\mathrm{Fe}_{3} \mathrm{O}_{4}$, and also to a minor extent of amorphized hematite. Recent studies show that the formation of yellow compounds depends both on the proportion of hematite and on the laser fluence [20]. For Gracia et al. [15] the irradiation residues being of nanometric size, they could be generated by a sudden hot-cold contrast. The latter explanation is in line with previous observations [14].

Our results fit quite well with these findings, although new questions are raised related to goethite, the presence of which we evidenced in our study by two complementary analytical methods. The transformation of hematite into goethite requires hydration, a process hard to figure in a very hot laser-generated plasma. The formation of maghemite (?$\mathrm{Fe}_{2} \mathrm{O}_{3}$ ) at the expense of hematite - maybe through an intermediate phase such as magnetite - would be more satisfactory from the point of view of thermodynamics. This yellow iron oxide has the same chemical formula as hematite but its crystal structure is similar to the one of magnetite. Unfortunately, the inflections typical of this mineral were not found on the second derivative of the diffuse reflectance spectra of our samples.

\section{Conclusion}

This work is one of the few studies performed on a natural sample and, to our knowledge, the only one analyzing a powdery gypsum-rich deposit from an urban monument located in a strongly polluted environment.

The combination of Raman spectroscopy and diffuse reflectance spectrometry has allowed to better understand laser yellowing: we suggest that the yellow appearance obtained upon laser irradiation is mainly due to the preservation of goethite, or of an iron containing phase having the same spectral signature as goethite in the visible range. The yellow appearance would thus be the consequence of a selective elimination of the black components (soots) from the powdery deposit, revealing then a colour linked mainly to a pre-existing phase. Hematite present in the material before irradiation would transform into a mineral having the same diffuse reflectance signature as goethite: this transformation would further accentuate the yellow hue. Keeping in mind that such a transformation is not thermodynamically allowed, an alternative explanation would be formation of a mineral close to maghemite at the expense of hematite. The question remains open.

Further investigations are necessary to accurately establish the different steps of these processes: XPS and XANES spectroscopies, electron diffraction under TEM are currently being performed, in order to better characterize the neoformed species, and understand the mechanisms of their formation.

Acknowledgements This study was partially funded by the French Ministry of Culture within the frame of the 2012-2014 Programme National de Recherche sur le Patrimoine Culturel. Many thanks to Karel Kunc for the English language editing.

\section{References}

1. J. F. Asmus, C. G. Murphy, and W. H. Munk, "Studies on the interaction of laser radiation with art artifacts," in Developments in Laser Technology II (R. Wuerker, ed.), vol. 41, pp. 19-30, 1974.

2. G. Orial in Preservation and restoration of cultural heritage, (Switzerland), pp. 469-479, Ecole Polytechnique Fédérale de Lausanne, 1996.

3. A. Giusti, C. Biliotti, and C. Samarelli, "Alcuni casi di utilizzo del laser nella pulitura dei marmi," OPD restauro, vol. 8, pp. 120-126, 1996.

4. G. Calcagno, M. Koller, and J. Nimmrichter, "Laser Based, Cleaning on Stonework" Restauratoren Blätter. Vienna: St. Stephens Cathedral. Special Issue: LACONA I, 1997.

5. C. Weeks, "The 'portail de la mere dieu' of amiens cathedral: Its polychromy and conservation," Studies in conservation, vol. 43, pp. 101-108, 1998.

6. P. Bromblet, M. Labouré, and G. Orial, "Diversity of the cleaning procedures including laser for the restoration of carved portals in france over the last 10 years," Journal of Cultural Heritage, vol. 4, Supplement 1, no. 0, pp. 17 - 26, 2003. Lases in the Conservation of Artworks - $\{$ LACONA $\}\{$ IV $\}$. 
7. M. Cooper and S. Sportun, "2005," in Proceedings in Physics, pp. 55-64.

8. J. Delgado-Rodrigues and A. Charola, Jerónimos Monastery, the conservation intervention, pp. 199-206. Lisboa: Cadernos IPPAR, 2006.

9. J. Delivre, Goupe de recherche sur le plâtre dans l'art, ch. Le Plâtre, l'art et la matière, pp. 365-373. Créaphis, 2001.

10. J. Delivre, "Laser cleaning: is there specific laser esthetics?," Journal of cultural heritage, vol. 4, supplement 1, pp. 245-248, 2003.

11. V. Vergès-Belmin, C. Oliveira, and O. Rolland in ICOM-CC 17th Triennial Conference (a. J. Bridgland, ed.), vol. 1703, p. 8, Melbourne, Australia: International Council of Museums.

12. V. Vergès-Belmin and C. Dignard, "Laser yellowing: myth or reality?," Journal of Cultural Heritage, vol. 4, supplement 1, pp. 238244, 2003.

13. P. Pouli, M. Oujja, and M. Castillejo, "Practical issues in laser cleaning of stone and painted artefacts: optimisation procedures and side effects," Applied Physics A, vol. 106, no. 2, pp. 447-464, 2012.

14. S. Klein, F. Fekrsanati, J. Hildenhagen, K. Dickmann, H. Uphoff, Y. Marakis, and V. Zafiropulos, "Discoloration of marble during laser cleaning by Nd:YAG laser wavelengths," Applied Surface Science, vol. 171, pp. 242-251, 2001.

15. in LACONA V, proceedings, Osnabrueck, (Germany), pp. 341346.

16. I.C.O.M.O.S.-I.S.C.S., Illustrated glossary on stone deterioration patterns - Glossaire illustré sur les formes d'altération de la pierre. ICOMOS.

17. C. Sabbioni, "Contribution of atmospheric deposition to the formation of damage layers," Science of The Total Environment, vol. 167 , no. 1-3, pp. 49 - 55, 1995. The Deterioration of Monuments.

18. V. Zafiropulos, C. Balas, A. Manousaki, Y. Marakis, P. Maravelaki-Kalaitzaki, K. Melesanaki, P. Pouli, T. Stratoudaki, S. Klein, J. Hildenhagen, K. Dickmann, B. S. Luk'Yanchuk, C. Mujat, and A. Dogariu, "Yellowing effect and discoloration of pigments: experimental and theoretical studies," Journal of Cultural Heritage, vol. 4, Supplement 1, no. 0, pp. 249 - 256, 2003. Lases in the Conservation of Artworks - \{LACONA $\{\mathrm{IV}\}$.

19. P. Pouli, D. C. Emmony, C. E. Madden, and I. Sutherland, "Studies towards a thorough understanding of the laser-induced discoloration mechanisms of medieval pigments," Journal of Cultural Heritage, vol. 4, Supplement 1, no. 0, pp. $271-275$, 2003. Lases in the Conservation of Artworks - $\{$ LACONA $\}\{$ IV $\}$.

20. C. de Oliveira, V. Vergès-Belmin, D. Demaille, and P. Bromblet, "Lamp black and hematite contribution to laser yellowing: A study on technical gypsum samples," Studies in Conservation, vol. 0, no. 0 , p. null, 0 .

21. S. Siano, J. Agresti, I. Cacciari, D. Ciofini, M. Mascalchi, I. Osticioli, and A. Mencaglia, "Laser cleaning in conservation of stone, metal, and painted artifacts: state of the art and new insights on the use of the nd: Yag lasers," Applied Physics A, vol. 106, no. 2, pp. 419-446, 2012.

22. M. Gaviño, B. Hermosin, V. Vergès-Belmin, W. Nowik, and C. Saiz-Jimenez, "Composition of the black crusts from the saint denis basilica, france, as revealed by gas chromatography-mass spectrometry," Journal of Separation Science, vol. 27, no. 7-8, pp. 513-523, 2004.

23. S. Ramirez-Martin, "Analyses quantitatives sur croûtes gypseuses," Tech. Rep. AFF MATT 14 119, 2014.

24. "Bulletin d'analyse," Tech. Rep. 1789-1, Service central des analyses C.N.R.S., 2013.

25. V. Fassina, L. Lazzarini, and G. Biscontin in Proceedings of the 2nd International symposium on the deterioration of building stones (N. Beloyannis, ed.), (Athens, sept-octob.1976), pp. 201211.
26. D. Neff, “Apport des analogues archéologiques à l'estimation des vitesses moyennes et à l'étude des mécanismes de corrosion à très long terme des aciers non alliés dans les sols."

27. N. Malengreau, J. Muller, and G. Calas, "Fe-speciation in kaolins: a diffuse reflectance study," clays and clay minerals, vol. 42, pp. 137-147.

28. P. Maravelaki-Kalaitzaki, "Black crusts and patinas on pentelic marble from the parthenon and erechtheum (acropolis, athens): characterization and origin," Analytica Chimica Acta, vol. 532, no. 2 , pp. $187-198,2005$.

29. Á. Török, T. Licha, K. Simon, and S. Siegesmund, "Urban and rural limestone weathering; the contribution of dust to black crust formation," Environmental Earth Sciences, vol. 63, no. 4, pp. 675693, 2011.

30. T. Skoulikidis, D. Charalambous, and P. Papakonstantinou-Ziotis, "Mechanism of sulphation by atmospheric so2 of the limestone and marble of ancient monuments and statues: Iii. further proofs of the validity of the galvanic cell model," British Corrosion Journal, vol. 18 , no. 4 , pp. 200-202, 1983.

31. S. Potgieter-Vermaak, R. Godoi, R. V. Grieken, J. Potgieter, M. Oujja, and M. Castillejo, "Micro-structural characterization of black crust and laser cleaning of building stones by micro-raman and $\{$ SEM $\}$ techniques," Spectrochimica Acta Part A: Molecular and Biomolecular Spectroscopy, vol. 61, no. 11-12, pp. $2460-$ 2467, 2005.

32. J. Zhang, A. J. Birnbaum, Y. L. Yao, F. Xu, and J. R. Lombardi, "Effect of fluence on the discoloration of marble cleaned with \{UV \} lasers," Applied Surface Science, vol. 253, no. 6, pp. 3083 -3092, 2007. 